\title{
Learning, change, and the utopia of play
}

\author{
Stuart Moulthrop
}

Received: 3 January 2007 / Accepted: 10 January 2007/ Published online: 1 March 2007

(C) Springer Science+Business Media, LLC 2007

\begin{abstract}
This article looks at some of the rhetoric surrounding video games and other forms of interactive software as additions or alternatives to school curricula. It focuses particularly on the need to articulate ways to "read" videogames in order to achieve significant cultural impact. Noting that reading, even as metaphor, tends to invoke in appropriate assumptions about writing and authorship, the article argues for a less backward-looking approach to newer forms.
\end{abstract}

Keywords Literacy $\cdot$ Video games $\cdot$ New media $\cdot$ Pedagogy

Double logics abound in this emerging global civilization. Rising tides lift some boats, but elsewhere breach levees. At home and abroad, wars in defense of democracy enlarge the scope of tyranny. The hyperconnectedness that draws people ever closer also sharpens the inwardness and intolerance of tribes. These days we can array and debate knowledge claims with wiki-wiki dispatch, yet a growing majority of Americans deny evidence that humans evolved from earlier species (Harris Interactive, 2006). In these information-enriched precincts of our freshly flattened world, we have never been so smart and free. The truth of this statement seems undeniable, no matter which reading one prefers.

Indeed, there is much talk about freedom these days, both in geopolitical and commercial terms, but the idea seems ill-defined as ever, and relevant messages are seriously mixed. The future of cultural production, and of learning, may well require highly independent, aggressively creative knowledge workers, yet the methods and assumptions of such people run strongly counter to dominant economic interests. As Yochai Benkler (2006) observes, "the tension between the industrial model of cultural production and the networked information economy is nowhere more pronounced than in the question of the degree to which the new folk culture of the

\footnotetext{
S. Moulthrop (ه)

Information Arts and Technologies, University of Baltimore, 1420 North Charles Street,

Baltimore, MD 21201, USA

e-mail: smoulthrop@ubalt.edu
} 
twenty-first century will be permitted to build upon the outputs of the twentiethcentury industrial model" (300). Thus Lawrence Lessig's famous debunking of Apple's erstwhile marketing pitch, "Rip, Mix, and Burn-It's Your Music" (203) (Lessig, 2004). In fact, buyers of iPods do not necessarily own the musical information they record on their hard drives, especially if it came from Apple's own marketing arm, which sells only limited licenses to store and play copyrighted content.

Yet while ownership of cultural assets does compel attention, it is not the only controversy posed by the growing adoption of digital, networked media. When it comes to emerging technologies of learning, especially videogames and interactive simulations, we might frame the primary question more in terms of process than product. As Katie Salen and Eric Zimmerman point out, highly interactive media such as games and simulations increasingly assume an "open culture," where the initial, limited participation inherent in interactive play opens into more radical possibilities. This design principle is evident in a large number of highly successful games, most notably the classic Sims series of Will Wright, where more than $90 \%$ of current game assets have been contributed by players (Salen \& Zimmerman, 2003: 540). As massively multiplayer games continue to grow in popularity, people engaged with this medium face a number of important questions:

A game designed as open culture allows players in some way to access the game structure and directly change its meanings. But what is the extent of this change? How deep is the exchange of meanings between the game and its context? Is the game system affected on an aesthetic level, as when the skins of game avatars are customized by players? Is the game system affected on the level of experience, as in a custom mod that adds new interactive possibilities? Or are the game rules themselves changed, at the level of code? How does each of these transformative effects change the cultural meaning of the game? (Salen \& Zimmerman, 2003: 538)

Successive questions in this list have less to do with modification and more with reproduction. Gamers who rewrite the underlying logic of an original product (no doubt with reckless disregard for legal jeopardy) are no longer simply consumers of that product. In an important sense, they become self-directed learners: teaching themselves to play the meta-game of game design, an activity that is fundamentally re-creative. Framing "games as open culture" moves us to ask if interactive software can ever be considered content in the common sense of data transmitted through a channel with high fidelity to its original form. On the contrary, it is probably better to approach games as we would any byproduct of Turing machines-less as content than as medium or mediation, systems intended not for inscription and transmission, but for recursive, adaptive permutation and play.

From the viewpoint of pedagogy, the shift from content to mediation aligns with theories of active or critical learning, which the linguist James Gee (2003) defines as "learning to think of semiotic domains as design spaces that manipulate us... in certain ways and that we can manipulate in certain ways" (43). This approach implies an independent, highly capable learner, and while this subject must situate herself with respect to existing communities of knowledge, she does so as a relatively free agent. Increasingly, Gee suggests, critical learners will fall out with traditional institutions: "better theories of learning are embedded in the video games many children in elementary and particularly high school play than in the schools they 
attend.... Is it a wonder, then, that by high school, very often both good students and bad ones, rich ones and poor ones, don't like school?" (7)

Meanwhile, extra-scholastic possibilities beckon. Gee calls attention to fantasy card games like $\mathrm{Yu}$-Gi-Oh, which are less like anything in Hoyle and more like Dungeons and Dragons, a game emphasizing improvisation over deterministic play. Games of this sort stimulate a great deal of autonomous learning, from informal, face-to-face tutorials to amateur Web sites offering instruction on fine points of strategy. In many cases, the creators of these resources are schoolchildren, presumably those same students disaffected by education, as we know it.

For some, these observations may suggest utopian fantasies about bricolage, cultural resistance, and independent action. As Benkler (2006) summarizes it, this position assumes "there is something normatively attractive, from the perspective of 'democracy' as a liberal value, about the fact that anyone, using widely available equipment, can take from the existing cultural universe more or less whatever they want, cut it, paste it, mix it, and make it their own" (276). Mindful of the demographic reach of interactive games, someone more naive than either Benkler or Gee might predict that the so-called gamer generation (born 1980 and later) will teach their elders a new approach to education, somehow reforming the classrooms through which they pass, especially as they reach high school and college. In this liberal or libertarian scenario, creative individuals, empowered by new technologies of learning, artfully sidestep educational bureaucracies, leading us to a world both brighter and more free.

Or so we are free to think, with sufficient suspension of disbelief. Those more attuned to the counterforces of flat-world capitalism may consign these imaginings to $\mathrm{Oz}$, or some similarly colorful Noplace visible only after a whack on the head. The world as we know it is not so cheaply redeemed; which brings us, again through the agencies of double logic, to that secular shadow of $\mathrm{Oz}$, the monochrome reality of red-state Kansas. In his political autopsy of his native state, Thomas Frank (2005) includes a profile of Kay O'Connor, an archconservative activist who voices a widely held assumption about public education:

O'Connor's solution to urban decline... is school vouchers and the low-wage economy. First we unleash market forces to improve the schools, then "these better schools will produce good workers, that will become attractive to more businesses, that will move in to get these good workers, who will work for lower wages, because [they're] from poverty families. They aren't expecting eighty thousand a year. They're content to work for six, eight, ten dollars an hour.' (172)

The subject of videogames does not come up in Frank's talk with Mrs. O'Connor, but if what Gee says about them holds, she would no doubt ban such things from her Republic, since she aims not to produce folks who can redesign their "semiotic domains," but docile, minimally skilled operatives destined for a wage niche somewhere between India and Ireland. In my own work experience, low-paying jobs require adaptability to procedural change (and declining real wages), but not so much innovation, invention, or critical intervention. Schools organized on the Kay O'Connor model might thus have little time for the ideas Gee or Salen and Zimmerman espouse, and seem likely to shun "open culture." Keenly aware of this fact, Gee concludes his study of videogames and learning with fighting words: "[Those] who think poor children should be content with schooling for service jobs 
don't like video games. They say they don't like them because they are violent. But, in reality, video games do violence to these people's notions of what makes learning powerful and schools good and fair" (205).

Gee's observation is crucially important, but like any call to radical action, both its meaning and implications must be carefully understood. Taking up our previous point about games as mediation, we might ask how the transformative potential of games for education is likely to be mediated by schools answerable to initiatives like No Child Left Behind and other supply-side interventions.

In one sense, mediation might imply a buffering or diversion of radical potential. Gee offers game-based learning as a subject of pedagogical study, not a curricular nostrum. While we should understand how games motivate autonomous learning, we may not need to incorporate $\mathrm{Yu}$-Gi-Oh or World of Warcraft into classroom practice. Indeed, games probably appeal to children largely because they are excluded from the formal culture of school. If this distinction is neglected, games might be used simply as extracurricular rewards: learn your lessons, earn playtime. Much worse, they might be brought into the classroom only as delivery systems for reinforcement of narrowly defined goals, i.e., as drill-and-practice resources for standardized tests. Needless to say, both these approaches strip away the dimension of "open culture" or re-creativity, since they would necessarily limit, not realize, possibilities for change.

However, there is also a second meaning of mediation, the one implicit in Marshall McLuhan's slippery dictum, "the medium is the massage." This kind of mediation, or as Jay Bolter and Richard Grusin (1999) name it, "remediation," gradually interweaves the cultural encoding of old and new technologies through a process or mutual adaptation or co-evolution (55). In this more positive scenario, educators who understand how games motivate independent learning would refashion traditional approaches to instruction, emphasizing active learning, agency, and discovery. Some games, and especially interactive simulations, might enter the curriculum, but they would be understood as parallel and complementary methods, not enhancements for content delivery.

Promoting the second scenario over the first requires political effort. Consciousness must be raised in many quarters and persuasion applied at various levels, in order to guide institutional change. Happily, figures such as Gee and Henry Jenkins have successfully begun this work, joined by younger colleagues like Salen and Zimmerman, Mary Flanagan, Kurt Squire, and Ian Bogost. Since many in the rising generation have themselves designed games or been closely involved in the process, they are probably well protected against the tendency to think of interactive software simply as a channel for content. In an open, recursively reproductive culture, any theory needs to be carefully informed by practice.

Still, at least one largely theoretical point needs attention, even as we begin the hard work of redesigning learning for the current century. On the way to his conclusions about the critical power of games, Gee makes a few claims that seem less easily laudable. One is his pronouncement that when "people learn to play video games, they are learning a new literacy" (13; emphasis original). Gee duly qualifies the term by referring to the widely accepted doctrine of plural, multiply mediated literacies, encompassing basic interpretive competence in everything from photographs to financial transactions. This is literacy by metaphor or analogy: as we learn to make words from letters, so we learn to process jump cuts in music videos, or maze geometries in first-person shooters, and so forth. 
The many-literacies doctrine plays well in a media-rich world, and Gee certainly understands its power and application. Yet at the end of the book, something of the old, black-letter meaning recurs. Logically enough, this happens when Gee touches that live wire of cultural polemic, the canard that new media must drive out old. To his credit, Gee rejects the usual hysteria, but in doing so he steps onto questionable ground:

Video games... will not replace books; they will sit beside them, interact with them, and change them and their role in society in various ways.... We have no idea yet how people "read" video games, what meanings they make from them. Still less do we know how they will "read" them in the future. (204)

A number of things seem striking about this passage. We might begin with the naturalization of reading as a mode of response to videogames, which seems curious for a medium that is, after all, enormously different from the written word. Yet Gee seems convinced that people will "read" games in the future, whatever that means. Or perhaps we should say, "read."” Like most scholars these days, Gee makes liberal use of inverted commas. (Those who reserve quotation marks for actual quotations are sweeping back the tide.) Here he uses them as typographic tweezers, picking up the verb to read like a nondescript specimen of dubious provenance. It is not the right word, but nothing better suggests itself, so we will have to deal in metaphor. Obviously no one reads a videogame like a book, so we refer to some process of deriving meaning, or forming a personal interpretation, that is (somehow, roughly) analogous in both media.

However, the putative analogy is ultimately problematic. Videogames and other forms of interactive software are nothing at all like books. Even if we prevent them from escaping to the wilds of open culture, these media belong not to the order of inscription, where information is recorded in relatively fixed and unitary form, but to another order where information must be selected, elicited, or filtered out by following one of many schemes for potential development. Espen Aarseth (1997) calls this type of discourse "ergodic" (4), or as we might say in humbler language, one that involves pathwork. Readers absorb and acquire. Browsers, surfers, interactors, adventurers, players-pathworkers all-explore and experiment. In pathwork, we do not process the symbol system to yield some ultimate, univocal meaning, but rather investigate and perhaps realize some of its possibilities: but always some, not all. Any contingent recognition extracted from the system is framed against a network of alternatives, experienced or imagined. Interactive systems make substantially different demands and inculcate ways of thinking about signs quite distinct from those enforced by writing-from which fact flow all Gee's valuable insights about games and critical learning. It seems very odd, then, to call this reading.

Some time ago, two wise scholars attached an important query to our irresistible tendency to adopt traditional language for newer media: "What are we likely to carry with us when we ask that our relationship with all technologies should be like that we have with the technology of printed words?" (Wysocki \& Johnson-Eilola, 1999: 349). In the case of videogames and learning, this question bears much repeating. In addition to the fact that what we do with games is probably not reading, we have to consider an important corollary or unvoiced assumption that comes with the metaphor.

Any act of reading assumes a prior act of writing. To think of videogames as objects that can be read is to suggest that they have somehow been written. Again, 
the language will not stretch this far without rupture. Though game design and production certainly involve large volumes of paper-based data, from concept pieces and business cases through scripts and design specifications, people seldom say, I am going to write a videogame today. The reasons are instructive.

While a few games have celebrated, marquee-name authors (titles by Will Wright, Sid Meier, and Shigeru Miyamoto come to mind), most do not; and even luminaries from the game designers' Walk of Fame must work with teams of developers to bring their ideas to market. Simply put, game design, like filmmaking, is fundamentally a social practice. Wright, Meier, Miyamoto, and others may some day inspire an auteur theory of game design, but as with cinema, this would be an academic abstraction imposed on an industry that depends on specialized, distributed, and relatively anonymous labor. Suggesting even metaphorically that videogames can be read implies that games have authors; and since our notions of authorship, at least in the literary vein, are invested with assumptions of individual, prophetic vision, we seem again to be setting off in the wrong direction.

So far this argument has been largely about semantics, or perhaps simply diction; but when we ask what we carry with us when we set up to read games-only to find in our luggage a notion of single authorship-we may come upon a more salient issue. Literary authors, after all, are not the only writers brought up to work in splendid isolation. From the dissertation forward, most academic humanists are also trained, evaluated, and promoted as solo performers. So when a professor of literature or media studies works with a software designer, student, or professional, each goes home to a very different social space. The professor repairs to a private office, the designer most likely to a cubicle farm. It is interesting to consider this difference in scenery as the architectural correlative of open versus closed cultures. The professor is expected to reflect and write, a process that for humanists generally ends in some kind of monograph. The software designer either contributes components to a team project, or perhaps manages the team, and the product of these labors comes with many names attached.

This distinction will probably be less evident to social scientists like Gee, who collaborate in writing and research more extensively than, say, the writer of this article. Yet this discrepancy may be all the more reason to insist that educators, those trained as humanists in particular, examine unvoiced assumptions about reading, writing, and authorship in socially complex media. If as suggested here, we have a choice between mediating away the progressive potential of games and simulations, or instead using them to radically reconceive educational structures, then we are not best served by concepts and language that look backward.

In particular we may want to watch out for reading and writing, at least to the extent these terms invite a nostalgia for solitary creation. The idea of games as open culture, like Benkler's "normative" values of participation and folk production, poses a very strong challenge to an educational system that still relies heavily on solo performance, especially in assessment measures like standardized exams. If we want to use new media to create alternatives to this system, we need to be wary of our own lingering investments. This awareness need not involve outright renunciation or negation. It may be possible to imagine a world of mixed architectures, one with both offices and cubicles, where the inevitable tension between these spaces is at least as much productive as otherwise. As Gee 
says, books and videogames will co-exist, but we may be much better served if they are able also to co-evolve.

\section{References}

Aarseth, E. (1997). Cybertext: Perspectives on ergodic literature. Baltimore: Johns Hopkins UP.

Benkler, Y. (2006). The wealth of networks: How social production transforms markets and freedom. New Haven: Yale UP.

Bolter, J., \& Grusin, R. (1999). Remediation. Cambridge: MIT Press.

Frank, T. (2005). What's the matter with Kansas? How conservatives won the heart of America. New York: Owl Books.

Gee, J. P. (2003). What video games have to teach us about learning and literacy. New York: Palgrave.

Harris Interactive (2006). Nearly two-thirds of U.S. adults believe human beings were created by god. http://www.harrisinteractive.com/harris_poll/index.asp?PID=581. 27 November (2006), 10:52 ET.

Lessig, L. (2004). Free culture: How big media uses technology and the law to lock down culture and control creativity. New York: Penguin.

Salen, K., \& Zimmerman, E. (2003). Rules of play: Game design fundamentals. Cambridge: MIT Press.

Wysocki, A., \& Johnson-Eilola, J. (1999). Blinded by the letter: Why are we using literacy as a metaphor for everything else? In Hawisher, G. \& Selfe, C. (Eds.), Passions, pedagogies, and 21st century technologies. U. Utah Press/NCTE. 